\title{
ENTRE OBSERVAÇÕES E REPRESENTAÇÕES: ESCRITA DE SI NAS NARRATIVAS DE UM EDUCADOR VIAJANTE (1923)
}

\author{
SARA RAPHAELA MACHADO DE AMORIM
}

Universidade do Estado do Rio Grande do Norte

RESUMO Explorar os sentidos da escrita de si nas narrativas de um educador viajante é o objetivo deste texto. Comissionado oficialmente como representante do Rio Grande do Norte, em 1923, Nestor dos Santos Lima lançou-se a conhecer o ensino dos centros de maior desenvolvimento educacional no Brasil, Uruguai e Argentina. Durante o deslocamento, o educador registra suas observações e representações, apresentadas no relatório Da Organização do Ensino Normal, Profissional e Primário no Sul do Brasil e no Rio da Prata (1923). Nas páginas deste escrito, é apresentado o viajante que transita por diversos lugares, estabelece novos contatos e aproveita seu espaço privilegiado de observação, escrita e reflexão, para emitir opiniões acerca do que viu, ouviu e experimentou. Procuro, nesta investigação, problematizar a escrita do relatório de viagem que se constitui, para além dos requisitos oficiais, também através da escrita de si, dos relatos, impressões e modos de enxergar o mundo, próprios do sujeito eleito para desempenhar a missão.

Palavras-chave: Relatório de Viagem. Educação. Escrita de Si.

ABSTRACT BETWEEN OBSERVATIONS AND REPRESENTATIONS:

\section{SELF-WRITING IN THE NARRATIVES OF A TRAVELING EDUCATOR (1923)}

Exploring the senses of self-writing in the narratives of a traveling educator is the purpose of this text. Officially commissioned as a representative of Rio Grande do Norte, in 1923, Nestor dos Santos Lima launched to learn about the education of the centers of greatest educational development in Brazil, Uruguay and Argentina. During his displacement, the educator records his observations and representations, presented in the report Da Organização do Ensino Normal, Profissional e Primário no Sul do Brasil e no Rio da Prata (1923). In the pages of this paper, it is shown the traveler who transits through 
different places, establishes new contacts and takes advantage of his privileged place of observation, writing and reflection to express opinions about what he has seen, heard and experienced. In this investigation, I try to problematize the writing of the trip report which constitutes beyond the official requirements, also through the self-writing, the reports, impressions and ways of seeing the world, that are proper characteristics of the person chosen to carry out the mission.

Keywords: Trip Report. Education. Self-Writing.

\section{RESUMEN ENTRE LAS OBSERVACIONES Y REPRESENTACIONES DE LA ESCRITURA DE SII EN LAS NARRATIVAS DE UN EDUCADOR VIAJERO (1923)}

El objetivo de este texto es explorar los sentidos de la escritura de sí en las narrativas de un educador viajero. Comisionado oficialmente como representante de Rio Grande do Norte, en 1923, Nestor dos Santos de Lima se lanzó a conocer la enseñanza de los centros de mayor desarrollo educativo en Brasil, Uruguay y Argentina. Durante el desplazamiento, el educador registra sus observaciones y representaciones, presentadas en el informe Da Organização do Ensino Normal, Profissional e Primário no Sul do Brasil e no Rio da Prata (1923). En las páginas de este escrito es presentado el viajero que transita por diversos lugares, establece nuevos contactos y aprovecha su espacio privilegiado de observación, escritura y reflexión para emitir opiniones sobre lo que ha visto, oído y experimentado. Busco, en esta investigación, la problematización de la escritura del informe de viaje que constituye, además de los requisitos oficiales, también a través de la escritura de sí, de los relatos, impresiones y modos de ver el mundo, propios del sujeto elegido para desempeñar la misión.

Palabras clave: Informe de Viaje. Educación. La escritura de Sí.

O que o relatório de uma viagem pedagógica pode apontar sobre quem o escreveu? Como perceber traços do pensamento e visão de mundo de um educador, a partir de uma escrita caracterizada por requisitos administrativos? Que relações existem entre viagem e viajante? Os relatórios de viagem, embora muitas vezes requeridos por autoridades educacionais, enquanto documentos oficiais, fazem parte do universo autobiográfico, pois revelam, para além das questões do ensino, as opiniões e subjetividades dos educadores viajantes.

Compreender as observações e representações de um educador viajante e perceber, nas entrelinhas, o desnudamento de suas ideias requer a reflexão sobre os diversos fatores que compõem o escrito produzido, investigando desde os objetivos que subsidiam a ideia, 
itinerário planejado, relações políticas, profissionais e pessoais, até às finalidades do trânsito. A busca pelo desenvolvimento da educação pública em consonância com o ideário de modernidade republicano era desejo dos educadores norte-rio-grandenses, claramente disseminados nas revistas e jornais, que circulavam no Rio Grande do Norte do início do século XX, e para obter aproximação com o que era desenvolvido em outros Estados do país e até em outros países, educadores eram designados delegados oficiais em missão.

Em 02 de maio de 1923, a bordo do transatlântico alemão Capitão Polônio, o educador Nestor dos Santos Lima inicia sua jornada de visitas e busca por novos conhecimentos acerca do ensino normal, profissional e primário. Designado em comissão oficial pelo governo do Rio Grande do Norte, foi enviado com o objetivo de visitar instituições, observando princípios e processos dos métodos e práticas desenvolvidos nos centros de maior cultura pedagógica do Brasil e do estrangeiro. Seu destino inicial foi a região do Rio da Prata, visitando, no Uruguai e na Argentina, as cidades de Montevidéu e Buenos Aires. O roteiro de volta contemplava a visitação dos Estados da região sudeste do Brasil: São Paulo, Minas Gerais, Rio de Janeiro e Espírito Santo.

Em meio aos apontamentos sobre a organização escolar, arquitetura, métodos e práticas, nas entrelinhas do texto, emerge a presença do escritor. Mas por qual razão este foi o educador escolhido para desempenhar tal missão? Pensar na viagem é refletir também sobre aquele que viaja, visto que antes do embarque, havia certa preparação cultural para que o aproveitamento pudesse ser satisfatório. Não era qualquer pessoa que viajava, de acordo com Mignot (2007, p. 253), era necessário “[...] conhecer pelo menos cem palavras do país visitado para ter acesso a números, moedas, passagens e alimentação, além de recomenda- ções pessoais ou de associações para serem usadas com discrição, quando absolutamente necessárias".

Viajar é uma prática social que possui diversos significados. Historicamente, os deslocamentos tiveram propósitos e finalidades diversas: de caráter religioso, militar, exploratório, políticas, econômicas, diplomáticas, literárias, culturais, de lazer, intercâmbio, viagem de caráter oficial ou particular. Os motivos vão mudando, adquirindo e produzindo outros sentidos. Ao longo do tempo, mudanças se processaram na realização das viagens, tanto em termos de materialidade quanto distâncias, velocidade, gastos, assim como "nas motivações [...] e nos sentidos e significados que as envolviam" (CHAMON; FARIA FILHO, 2007, p. 40).

A formação do sujeito indicaria, portanto, sua possibilidade de ser tradutor/mediador de realidades distintas. Os sentidos de uma viagem variam de acordo também com quem viaja, já que a trajetória de vida do indivíduo exerce influências sobre as escolhas que realiza, indica a percepção que tem do social, assim como sua visão de mundo. Perceber a natureza e complexidade dos acontecimentos, a dinâmica de uma vida, é primordial, pois o viajante não se desloca apenas nas distâncias geográficas, mas em suas subjetividades, transitando por diferentes contextos a partir de suas motivações.

\section{As credenciais do viajante}

Compreender os aspectos da intimidade de Nestor Lima, de sua vida e dos relacionamentos que permeiam as observações e representações do relatório de viagem, suscita, antes de tudo, investigar seus ambientes de formação e convívio social, visto que os indivíduos interagem e também produzem o espaço social a partir de tais interações. Investigar o que levou este educador, dentre tantos outros, a 
ocupar este posto de representante educacional de um Estado, é falar também de suas origens, suas referências e conhecimentos. Nas primeiras décadas do século $X X$, o prenúncio da modernidade era favorável aos que dominavam as práticas de leitura e escrita. De acordo com Morais (2009, p. 76), "na sociedade que se formava, somente aos letrados seria concedida a senha de participação na nova ordem. Não havia, portanto, mais espaço para quem não soubesse ler o mundo através das letras do alfabeto".

Dialogando com Clarice Nunes, que examinou a construção social da identidade de Anísio Teixeira, Mignot (2002) assinala a importância de recuperar o percurso de formação para que não se dilua a especificidade da trajetória dos indivíduos e seus múltiplos significados. A interpretação de mundo do indivíduo pode variar a partir do lugar social que ocupa. Para tanto, busco entender qual a posição de Nestor Lima na organização educacional norte-rio-grandense e, além disso, conhecê-lo em suas múltiplas dimensões, de vida, formação e atuação profissional, que conduziram para o destino de educador viajante.

Nestor dos Santos Lima nasceu em 01 de agosto de 1887, em Assu, município do Rio Grande do Norte. Sua mãe, Ana Souto Lima foi a responsável pelos estudos primários e após os primeiros ensinamentos, matriculou-o para estudar no Atheneu Rio-Grandense. Aos treze anos de idade, ingressou no Curso Secundário, concluído no Liceu Paraibano, em 1904. Em 1905, matriculou-se na Faculdade de Direito do Recife, pela qual recebeu o título de Bacharel em Ciências Jurídicas e Sociais, em 16 de março de 1909. Prestou concurso para a Escola Normal de Natal. Em 14 de março de 1911 foi nomeado, pelo Governador Alberto Maranhão, para exercer o cargo de Diretor desta instituição de ensino, permanecendo nesta função até 1923.
Conhecer a trajetória de vida e formação de Nestor Lima permite o entendimento dos espaços que ele ocupou e como alguns destes viabilizaram a realização da viagem ao sul do Brasil e países vizinhos. Um exemplo disto é a sua atuação à frente da direção da Escola Normal de Natal, onde o educador tinha, dentre as suas responsabilidades, que descrever o funcionamento da instituição por meio de relatórios institucionais. Em 1912, este intelectual se utiliza desta escrita administrativa como um espaço para que pudesse propor, ao governador, uma viagem com o objetivo de observação das práticas e do funcionamento de instituições educacionais nos Estados que representavam maior desenvolvimento nas questões do ensino.

No ano seguinte, foi convidado para representar o Rio Grande do Norte na tarefa de observar o funcionamento de instituições educacionais, no Rio de Janeiro e em São Paulo. Deste trânsito, resultou seu primeiro relatório de viagem, intitulado Melhoramentos Técnicos do Ensino Primário e Normal (1913), onde Nestor Lima escreveu não apenas sobre as instituições visitadas, mas se revela ao passo que, agradecendo ao governador do Estado a confiança nele depositada, escreveu sobre como se tornou o sujeito escolhido para esta missão:

Cabe-me, antes de tudo, louvar a V. Exa. o patriótico empenho constantemente demonstrado pelo progresso do nosso ensino primário e normal, em boa hora reformados pelo decreto no178 de 29 de abril de 1908, empenho que mais uma vez se comprovou com o aplauso e cumprimento dados por V. Exa. à ideia que avantei nas considerações gerais do Relatório da Escola Normal de setembro do ano passado, qual era mandar-se, em comissão e uma vez por outra, aos centros de maior cultura pedagógica do país ou do estrangeiro, profissionais do nosso ensino que, conhecedores das necessidades e condições do meio a serviço de seu cargo, pudessem aí adquirir subsídios para o aperfeiçoamento contínuo da nossa tecnologia didática. (LIMA, 1913, p. 3-4) 
Nestor Lima versa sobre si, ao apresentar suas relações políticas, profissionais e pessoais, que ganham relevo à medida que o educador narra seus deslocamentos, dado que seus contatos com as autoridades de outras regiões eram por vezes mediados por cartas, telegramas e demais documentos que indicassem as razões e objetivos de suas visitas. Suas primeiras palavras no relatório dedicam-se à prestação de contas e agradecimento:

Ainda penhorado pela cativante gentileza que V. Exa. me dispensou, incumbindo-me de observar na Capital Federal e no Estado de São Paulo, os melhoramentos introduzidos na técnica do ensino primário e normal, aplicáveis aos estabelecimentos oficiais deste estado, venho dar conta da minha missão e expressar, de publico, meu mais profundo reconhecimento. (LIMA, 1913, p. 3)

O viajante comissionado possuía algumas obrigações que iam além das visitas, dentre estas, "a escrita de um relatório de viagem, escrita esta que não se esgotou nas obrigações daquele que viajava pela comissão, mas transformou em partilha dos conhecimentos e impressões pessoais e, até mesmo intimas daquele que escreve" (MIGNOT; SILVA, 2011, p. 441). Pensar sobre como a viagem, enquanto tema que se expande em diversas épocas e culturas, é também perceber como ocorrem as construções dos relatos que refletem os interesses, inquietudes e preocupações de uma época, representados em seus registros, pelo viajante escritor.

A articulação entre o planejado e o percorrido de um itinerário constitui a estrutura básica do relato. Observação, reflexão e expressão. O narrador vai adentrando em umas ou outras cidades e lugares que, com mais ou menos detalhes, são descritas ao longo do seu registro. Há uma sequência cronológica onde o narrador conta, com mais ou menos detalhes, de acordo com a relevância que confere a cada situação, sobre o desenvolvimento e a história da viagem. As descrições dos espaços visitados, as referências aos sujeitos encontrados, um discurso que toma os moldes dos motivos que o levaram a esta viagem. Correspondências, itinerários, tempo e lugares subordinados à narração e intenções do sujeito que descreve. Nesse sentido, o tempo apresenta-se como um importante elemento, porque viagem e escrita seguem uma ordem específica, dado que não há escrita de relato de viagem sem deslocamento. Sobre as especificidades do relato, Luís Albuquerque-García destaca que:

Los 'relatos de viajes' responden a mi entender a tres rasgos fundamentales que se complementan con algunos más que luego veremos: (1) son relatos factuales, en los que (2) la modalidad descriptiva se impone a la narrativa y (3) en cuyo balance entre lo objetivo y lo subjetivo tienden a decantarse del lado del primero, más en consonancia, en principio, con su carácter testimonial, (ALBUQUERQUEGARCíA, 2011, p. 16) ${ }^{1}$

Trilho, portanto, um caminho através da escrita deste educador, levando em consideração todas as liberdades e limites que ele se permitiu fazer na construção de seu texto. Percebo que não se trata de uma prática de viagem para realizar cópias de modelos educativos, mas de refletir sobre o que se desenvolve, traçando por certas vezes uma aproximação com instituições e práticas do seu Estado de origem.

A preocupação em publicar o visto e o vivido nos tempos de viagem aponta para uma compreensão da dimensão política deste tipo de escrita. A divulgação era o meio de chamar a atenção dos diversos setores para o compro-

1 “Os 'relatos de viagens' respondem a meu entender a três traços fundamentais que se complementam com alguns mais do que veremos: (1) são relatos factuais, em que (2) a modalidade descritiva, impõe-se a narrativa e (3) em cujo balanço entre o objetivo e o subjetivo tendem a inclinar-se do lado do primeiro, mais em consonância, em princípio, com o seu carácter testemunhal". 
metimento com projetos, grupos e interesses, tornando possiveis as intervenções no sentido de manutenção, mudanças ou reformas educacionais. A descrição predomina no relato e configura um discurso que desenvolve a narrativa, compreendendo os lugares visitados na travessia, assim como todo o entorno da experiência do viajante, pessoas, situações, costumes, mitos etc. As representações que descrevem objetos, espaços e personagens revelam o protagonismo do relato e localizam quem as escreve em um lugar de privilegio que permite tais vivências. A narrativa então construída por um sujeito de múltiplas dimensões sofre influências diretas de sua visão de mundo e objetivos:

Reflexão transformada em escrita, em que o olho era ordenado pela mão, o relatório era uma prestação de contas ao governo de sua viagem comissionada, ao mesmo tempo em que era momento de compartilhar percepções, opiniões e conhecimentos sobre um outro com seus contemporâneos. (CHAMON; FARIA FILHO, 2010, p. 19)

Percebo que apesar de endereçado ao governador do Estado, o relatório parece ter sido escrito também para ser lido por leitores outros, já que a divulgação das experiências de viagem ultrapassaram as laudas do relatório oficial e povoavam jornais e revistas que buscaram entrevistá-lo e divulgar as experiências vividas pelo viajante. Do mesmo modo, em 1923, escreveu no preâmbulo de seu texto, dirigindo-se ao governador, que neste segundo momento o incumbiu para esta tarefa, e destaca que ter sido enviado através deste político, facilitou suas relações com os especialistas na questão do ensino nas localidades visitadas:

Permita, porém, V. exc. Que comece agradecendo-lhe cordialmente a confiança que me confiou e o ensejo que tive de conhecer de perto novos centros de cultura educacional, facilitando-me, destarte, o contato com reputados es- pecialistas da questão do ensino, tanto no sul do Brasil, quanto nos povos irmãos do Rio da Prata. (LIMA, 1923, p. 3)

A subjetividade que emerge destas palavras iniciais, também acentua seus sentimentos em relação à missão e impressões acerca das relações internacionais e interestaduais, destacando como está organizada sua narrativa e afirmando que os seus interesses o conduziram a determinadas observações. "Como sejam muitos os aspectos das observações realizadas, tratarei por partes dos diversos assuntos que me interessaram, subdividindo-os pelos países e estados que visitei [...]" (LIMA, 1923, p. 4).

A formação de Nestor Lima, aqui discutida, não está restrita ao período que antecede sua jornada, entendendo que a viagem também possui dimensão formativa e os sujeitos se desenvolvem por meio de influências várias, seja a partir das experiências, aprendizagens e relações constituídas ao longo da vida. Considero, assim, a singularidade de sua trajetória, como também os modos de ação e interação com os outros e os diversos e diversificados contextos sociais e culturais. Uma trajetória de vida é, portanto, também um percurso de formação.

Nestor Lima deixa vestígios de si também por meio dos modos como se constrói a partir das experiências que o levam à ampliação dos espaços de visitação, na segunda viagem, assim como a organização das ideias que se organizam de maneira diferenciada no relatório de seu segundo intercâmbio pedagógico. Um documento de cento e vinte páginas - quase o triplo, se comparado ao anterior - é organizado de acordo com os assuntos, países e Estados que percorreu. Ao narrar sua jornada, confere ao seu relato a responsabilidade de representá-lo, situando-o em um lugar específico no social, visto que se trata do sujeito que, possuindo as credenciais necessárias para 
esta missão, e após tê-la desempenhado, não retorna do mesmo modo que se lançou.

\section{Um viajante rumo ao estrangeiro}

Nestor Lima destacou que, no decurso das informações que veicularia, pretendia demonstrar os propósitos educacionais tal como os sentiu nas classes durante as visitas nas instituições de formação. O relatório foge da neutralidade e impessoalidade de um documento oficial, pois não se caracteriza apenas como um conjunto de informações acerca do funcionamento dos locais, mas é permeado por impressões e opiniões particulares. Conduz o leitor a transitar pelas instituições visitadas por ele, surgindo neste caminho suas representações sobre cada espaço visto. No percurso, escreve ainda sobre as aproximações e distanciamentos da educação que observou em relação a que era desenvolvida nas escolas do Rio Grande do Norte.

Por entre as observações e representações, dialogo com Roger Chartier, que reflete sobre a existência de categorias que organizam e constroem a representação como uma prática social:

O trabalho de classificação e de delimitação que produz as configurações intelectuais múltiplas através das quais a realidade é contraditoriamente construída pelos diferentes grupos; as práticas que visam fazer conhecer uma identidade social, exibir uma maneira própria de estar no mundo, significar simbolicamente um estatuto e uma posição; por fim, as formas institucionalizadas e objetivadas graças as quais uns 'representantes' (instâncias coletivas ou pessoas singulares) marcam de forma visivel e perpetuada a existência do grupo, classe ou comunidade. (CHARTIER, 1990, p. 23)

A visão de mundo do professor viajante, o que considerava correto e adequado para o desenvolvimento educacional e a formação sociocultural dos educandos, com base em princípios ideológicos, eram questões expres- sas em sua escrita. Considero seu texto como uma "prática discursiva produtora de mediações culturais, cujos efeitos aparecem nas estratégias de apropriação de determinadas ideias, conceitos e modelos e na recusa explícita" (SCHUELER, 2007, p. 107), construído com base não somente no que expressa, mas também nos possíveis silenciamentos.

O educador viajante certamente fez seleções entre as relações, observações que desejou representar no registro de sua viagem. Tantas vezes ao logo do percurso observou, criticou, exaltou, comparou. Suas apropriações e representações, construídas a partir das práticas pedagógicas nos países estrangeiros e demais Estados do Brasil, transitam do total encantamento ao distanciamento crítico, do olhar distraído à observação atenta, da análise do geral ao detalhamento do negligenciável, do projeto político às práticas cotidianas escolares. Na leitura do relato de viagem, o autor permite aos leitores que possam estar imersos no contexto de formação e instrução que afirma ter observado, compartilhando com estes as suas interpretações sobre outras culturas, povos, organizações sociais, assim como os conhecimentos que acumulou na experiência de viagem.

As relações internacionais e interestaduais são destacadas no item "Intercâmbio Pedagógico". Nele, escreve sobre diversas questões sociais, a exemplo da relação infundada de ciúmes e orgulho entre Brasil e Argentina, destacando o papel da imprensa para a disseminação deste tipo de ideia. Alertava que pouco deveria importar a voz apaixonada da imprensa mal orientada, que trabalhava a serviço dos negocistas e sua visão dos lucros nas compras de armamentos, preparando assim a ruína dos países amigos e irmãos. 0 discurso circunscreve-se à necessidade de haver um ensino que possibilite a ampliação das redes e relações entre brasileiros e argentinos. 
Os trâmites que dizem respeito às relações internacionais, a exemplo da autorização requerida para sua visita no país estrangeiro, são citados como etapa da atividade profissional, seguidos de menções pessoais relacionadas às atitudes por parte dos responsáveis pelos processos burocráticos:

Conhecedor das necessidades que me levavam ali, o Consul Brasileiro comunicou-se logo com o dr. Enrique Loudet, um notável médico argentino e grande amigo do Brasil, pertencente ao Corpo Médico Escolar do Conselho Nacional de Educação, expondo-Ihe o fim da minha visita. $E$, incontinente, transportando-me eu ao Conselho Nacional, fui lá recebido pelo dr. Loudet, que foi o liame dos meus interesses com o pessoal dirigente e docente do ensino buenairense. (LIMA, 1923, p. 35)

Em meio a estes trâmites, mencionou as cartas enviadas ao Ministro do Exterior Cônsul brasileiro Alberto Baez Conrado, assim como posteriormente ratificou o intermédio que o deputado José Augusto fez a alguns dos seus amigos em São Paulo. "Nosso eminente representante, dr. José Augusto me recomendara por telegrama a vários amigos seus, que ali são autoridades escolares" (LIMA, 1923, p. 55). Ainda, dentre os contatos que the abriram portas para que pudesse adentrar nos locais que desejava visitar.

Sobre as relações internacionais assinala:

Do Uruguai, especialmente cujas tradições de confraternidade com os brasileiros se me patentearam exuberantemente, tive ocasião de ser portador das saudações mais efusivas da parte das alunas dos cursos normais e dos cursos primários adiantados para as suas colegas deste Estado, saudações em que se sentem os anelos de amizade duradoura e sincera daquelas almas jovens que, ao contato com o humilde funcionário deste Estado, vibraram em demonstrações inequívocas de salutar sentimento intra-continental. (LIMA, 1923, p. 5-6)

Suas opiniões e impressões das relações interpessoais abrem espaço para as observações realizadas nestas localidades. 0 ponto de partida é Montevidéu. Antes de escrever sobre a visita aos espaços educacionais, o autor dedicou algumas linhas para falar dos trâmites necessários para que a visita acontecesse. Menciona as cartas obtidas com o ministro do exterior, seguindo orientação do governador Antonio de Souza, e que o apresentavam como enviado especial ao cônsul brasileiro Alberto Baez Conrado, dirigindo-se em seguida ao presidente nacional do ensino primário e normal, Dr. Juan Aguirre Gonzales. Nestor Lima disserta atento, inclusive sobre as questões do vestuário:

Primeiramente, o vestuário feminino em Montevideo, posto que estivesse começando o inverno, é, em regra de indiscutivel decoro. Além da natureza dos tecidos usados: caxemira, lã, malhas reforçadas, notam-se a discrição das toilettes, o seu razoável apuro, mesmo a sua elegância, segundo os figurinos e a moda; mas, extreme dos exageros e das requintadas esquisitices que tendem a prejudicar a inestimável virtude do pudor no sexo amável. (LIMA, 1923, p. 30)

Ele se posiciona sobre as questões que dizem respeito às vestimentas e à moral e comenta que esta virtude de trajar diz bem dos sentimentos e da moral do povo uruguaio. Ainda na mesma página, reforça que não lhe passou despercebida a proibição contida em um decreto arquiepiscopal que se lê na catedral de Montevidéu pela qual são excluídas dos sacramentos da igreja as pessoas que ali se apresentarem com soberba e sensualidade. E, logo acrescenta, que "considera-se soberba e sensualidade o traje indecoroso da mulher, quando não chegue, com manga, à altura do cotovelo e, com o decote, ao pé do cabelo" (LIMA, 1923, p. 31). Sobre as vestimentas, acrescenta ainda o uso do avental escolar, que tanto as docentes como as alunas, desde pequenas, o utilizavam.

Menciono em alguns momentos do texto o termo intercâmbio, não escolhido aleato- 
riamente, mas por perceber que o educador não só viaja em busca de novas práticas, como também leva suas experiências aos espaços visitados. Como exemplo, destaco sua visita à Escuela Normal para Niñas, onde, além de apontar características do prédio, das classes e da prática pedagógica, que segundo ele "a aprendizagem da técnica pedagógica está ali, porém, bem mais apurada que entre nós" (LIMA, 1923, p. 15), escreve sobre o momento que foi convidado a falar sobre métodos de leitura de Pedagogia e Psicologia Infantil:

Fui, afinal, convidado para falar àquela classe: acedi e falei em vernáculo brasileiro, a pedido insistente das ouvintes. Comecei recordando que àquela hora, eram quatro da tarde no $\mathrm{Na}$ tal, estaria eu em face das minhas alunas do 40 ano a dizer-lhes o que me convidaria a dizer ali: a opinião acerca de métodos da leitura inicial. Estabeleci os princípios, discuti a tese e demonstrei, segundo a minha prática pessoal, as excelências do método analítico de sentenciação. (LIMA, 1923, p. 16)

Neste momento, o viajante conhece e se dá a conhecer, numa busca de legitimação intelectual em diferentes ações. Sobre a noção de legitimação, Silva (2012, p. 32) entende que se deve "considerar os processos e modos de obtenção de uma legitimidade ou aprovação entre os membros de uma coletividade". É interessante perceber a sutileza das representações de si que o escritor apresenta no relatório, pois penso que o que é descrito não diz respeito apenas ao visto e vivido pelo viajante, mas relaciona-se com uma série de interesses que precediam ou resultariam desta experiência.

O educador viajante discorre acerca do que viu, ouviu, imaginou, representou. As informações que veicula caracterizam os cenários dos ambientes visitados, seguidas de suas opiniões sobre o que se apresentava diante de seus olhos. "Tudo nos une, nada nos separa" é o que diz sobre a sua visita à Escuela Estados Unidos del Brasil:
Vi, com orgulho, em todas as salas e em todos os quadros, as bandeiras brasileira e argentina entrelaçadas, frases de saudação, carinho e homenagem ao Brasil. 0 Croquis do Brasil se desenhava por toda parte. Ouvi poesias, brasileiras vertidas para o castelhano. Li cartas de saudações de escolas brasileiras às argentinas, especialmente da Escola Deodoro do Rio de Janeiro. À saída estavam formadas as classes no pátio interno, desfraldados os dois pavilhões brasileiro e argentino, quando foi cantado o Hino Nacional Brasileiro e, logo após, o Hino Nacional Argentino. (LIMA, 1923, p. 39)

Após percorrer tantas outras instituições das quais descreve o funcionamento e a organização, nas páginas do seu relatório, destaca que ao fim das visitas buscava reencontrar as autoridades que lhe conferiam o passaporte de ingresso nas instituições, com o intuito de se dispor para o que fosse necessário, através de votos de simpatia e cordialidade. A bordo do vapor fluvial Ciudad de Buenos Aires, retirou-se de Montevidéu às 22:00 horas da noite do dia 09 de maio de 1923 em direção a Buenos Aires, chegando à capital da República Argentina às 08:00 horas do dia seguinte. Afirmou ele, ser este um dos lugares que mais desejava apreciar: "um dos mais antigos anseios de minha carreira no ensino era conhecer de perto o adiantado centro de cultura que é a capital da República Argentina. Acostumado a admirar os seus progressos, nos diversos aspectos da sua civilização aprimorada, desejava desde muito pôr-me em contato com aquele povo irmão e com seus institutos pedagógicos" (LIMA, 1923, p. 34).

Apresentando-se ao Cônsul brasileiro Alcino dos Santos Silva que, segundo ele, lhe abriu as portas do consulado e de sua residência, num gesto de acolhida cativante e simpática. Dr. Alcino o apresentou ao Dr. Henrique Loudet, médico argentino pertencente ao corpo médico escolar do conselho nacional de educação que, ao ser informado da finalidade da 
visita de Nestor Lima, o apresentou ao inspetor e subinspetor das escolas da capital, José Rezzano e Francisco Herrera. Nestas visitas, foi acompanhado pelo inspetor de primário Heloy Fernandez Alonso.

Em sua fala transparecem também as possiveis tensões que envolviam a imprensa, a economia e as questões políticas dos dois países que, de certo modo, contribuíam para as disputas, que considerava infundadas, entre os dois países. "Pouco nos importe a voz apaixonada da imprensa mal orientada, a serviço dos negocistas que, com a visão dos lucros na compra de armamentos, tendem a preparar a ruina dos países irmãos e amigos de sempre" (LIMA, 1923, p. 6). Fez menção à cordialidade por parte dos argentinos, como também alerta para a necessidade de pensar questões diplomáticas entre Brasil e Argentina, assim como a formação das futuras gerações que era vista como solução às divergências que permeavam por muitas vezes os discursos dos brasileiros e argentinos:

Façamos barreira a esses ódios sem motivo e solidifiquemos no espírito das novas gerações aqueles tradicionais sentimentos de amizade e cordialidade que sempre existiram entre as duas nacionalidades. Infiltremos no espírito das gerações de futuro uma política de confiança, porque, força e dizer que não tivemos razões que justifiquem tais desconfianças. Só por vaidade, orgulho e despeito, sentimentos de tão baixa cotação entre os indivíduos, não se devem nem podem inspirar as nações entre si. Cada qual tem razão para sentir-se bem com seu progresso e adiantamento; mas, que isso, em vez de supor hegemonias e provocar rivalidades, deveria inspirar simpatias e desejo de aproveitamento recíproco das realizações de progresso de cada um. Faço meus estes votos cordiais do professorado argentino e prouvera que a consciência nacional os ouvisse, prosseguindo-se de lado a lado, numa política de confraternização assaz necessária ao nosso aperfeiçoamento. (LIMA, 1923, p. 6)
Afirma que da Argentina trouxe idênticas demonstrações de simpatia dos alunos, fazendo referência também à constante e preocupação do corpo docente, em especial aos sujeitos com os quais conviveu durante a permanência nas terras estrangeiras, os inspetores Fernandez Alonso e Julio Picarel. Destacou que o sentido essencial destas relações era de que os profissionais da educação na mocidade fundamentassem os laços de cordialidade e as relações com as nações vizinhas e irmãs, que compartilharam de semelhantes problemas e vitórias, mas que "[...] sem razão plausível, andam inspiradas em sentimentos, talvez de ciúme e orgulho, a enredarem-se em reciproca desconfiança, capaz de cavar o desmoronamento e a ruina das civilizações que temos conseguido fazer, com a possibilidade de luta injusta e injustificada entre Brasileiros e Argentinos" (LIMA, 1923, p. 6).

lanni (2000) afirma que à medida que o olhar do indivíduo transita pelos espaços geográficos e históricos, atravessa zonas fronteiriças e períodos demarcados temporalmente, o que ocasiona em muitas outras travessias, que demarcam as viagens. Este fato denota-se em muitos campos do conhecimento, quando as reflexões são realizadas na medida em que o olhar é lançado por lugares distintos e por outros momentos históricos. Segundo ele, a inquietação e a interrogação caminham lado a lado, com o risco de encontro com o óbvio ou o incomum, o novo ou encantador, o outro ou até mesmo de encontrar-se a si mesmo.

Para me aproximar da intimidade das ideias e objetivos de Nestor Lima, do que lhe causava estranhamento ou encantamento, busquei enxergá-lo no que the era peculiar, nas especificidades que o caracterizavam por meio da escrita. Considero relevante também compreender a viagem em sua complexidade, que, no diálogo com impressos datados do período, fornece indícios de organização, sentidos, 
razões das viagens, trocas culturais, dimensão formadora, locais e sistemas de ensino. Percebi que o intelectual, através da passagem por diferentes instituições, buscava, de modo pessoal, representar-se e legitimar-se no cenário educacional. 0 movimento de perseguir os rastros deste educador, através da sua escrita e do que manifesta de si, em sua narrativa, resulta na revelação de suas redes de sociabilidade e sentido dos contatos estabelecidos.

A cada novo ambiente visitado, tratandose de instituições educacionais ou não, Nestor Lima apresenta suas impressões pessoais, socializadas a partir da descrição de suas vivências nos respectivos espaços, assim como o legado, inclusive material, que deriva de cada novo contato estabelecido. As linhas compostas por descrições e impressões escritas no relatório de viagem apontam os caminhos pelos quais Nestor Lima conduz seu leitor a conhecer suas redes e os espaços de sociabilidade. Isto é perceptivel desde o telegrama que o incumbiu de sua missão, uma correspondência que representa o estabelecimento de relações e delega atribuições ao educador viajante. Assim, sigo, como denomina Venancio (2001), do texto para o contexto e do contexto às redes, identificando, a partir dos registros escritos, os atos e as práticas cotidianas que permitem vislumbrar traços de relações pessoais.

\section{A singularidade revelada no encontro: percorrendo redes de sociabilidade}

Qual a importância dos relacionamentos interpessoais para a realização de uma atividade profissional? Observo que Nestor Lima se apresenta por meio das relações que estabelece e no contato com outro revela a si mesmo. Pensar no status conferido ao viajante e a espécie de certificação cultural que lhe é dada, é também discutir a teia de sustento que se forma por trás deste envio. Uma esfera composta por educadores e políticos que se articulam em busca da realização de um projeto, o desenvolvimento da educação popular:

Ninguém se forma no vazio. Formar-se supõe troca, experiência, interações sociais, aprendizagens, um sem fim de relações. Ter acesso ao modo como uma pessoa se forma é ter em conta a singularidade de sua trajetória e, sobretudo, o modo singular como age, reage e interage com seus contextos. Um percurso de vida é assim um percurso de formação, no sentido em que é um processo de formação. (MOITA, 1992, p. 62)

Compreendo os esforços da viagem empreendida por Nestor Lima, enquanto uma ação reveladora da motivação de ampliar e fortalecer contatos e alianças, o que ajuda a dimensionar suas redes de sociabilidade, apoio e prestígio, num movimento de busca por afirmação, em meio aos diferentes grupos, contribuindo para o entendimento das categorias de análise intelectuais e as sociabilidades a partir de seus microclimas, tensões e clivagens internas (SIRINELLI, 2003), evidenciadas "num jogo de omissões, sanções e exaltações possibilitadas através da escrita" (SIMMEL, 1997, p. 168).

Transitava em diferentes instituições e espaços, conhecendo pessoas, fortalecendo laços, redes e alianças. É, portanto, a partir de sua escrita que percebo o destaque dado a cada sujeito citado no relatório, devidamente localizado em seu ambiente de trabalho e, algumas vezes, com informações a partir de sua relação pessoal ou profissional com o indivíduo mencionado. Ele destaca, por exemplo, que, em Buenos Aires, fez as visitas acompanhado do Inspetor do Ensino Primário, Eloy Fernandez Alonso “[...] que convidado para acompanhar-me nas visitas às escolas primárias, normais e profissionais, tornou-se um cicerone gentil e atencioso por todo o tempo dessas visitas" (LIMA, 1923, p. 35). 
No meio intelectual, os processos de transmissão cultural são essenciais no interior das redes. A parceria e amizade, como também o contrário, a rivalidade, rupturas e brigas, desempenham igualmente um relevante papel. Esta dimensão deve ser levada em consideração, visto que as redes são permeadas tanto pelo afetivo quanto pelo ideológico. No relatório de viagem de 1923, Nestor Lima, ao citar alguns dos sujeitos, destaca a consideração e respeito, em especial, por seus conterrâneos ou condiscípulos da Faculdade de Direito de Recife. É importante ressaltar que instituições como esta, formavam aqueles que provinham das camadas mais abastadas e, posteriormente, atuavam nos setores públicos, seja por meio da política, saúde, educação ou demais áreas.

Ao investigar os processos de sociabilidade identificados em Nestor Lima, entendo as ações deste intelectual como indissociáveis das interfaces que a permeavam: os aspectos políticos. "[...] Pois esta história dos intelectuais remetia obrigatoriamente, por algumas de suas facetas à história política [...]" (SIRINELLI, 2003 p. 234). Neste ponto, a escrita constitui uma prática de estabelecer e manter uma relação de redes políticas, sociais e intelectuais; a sociabilidade expressa nos impressos e que se dá no interior das estratégias de relacionamento pessoal e profissional.

Nestor Lima também fala sobre si, ao apresentar em sua narrativa a constituição de uma rede de sociabilidade. Mas de onde derivam essas relações que, de certo modo, o conduziram aos lugares que visitou? Quais espaços frequentava? Quem eram as pessoas que integravam suas redes de conhecimento e sociabilidade? As relações estabelecidas por Nestor Lima configuram-se no estudo como uma relevante categoria de reflexão, uma vez que busco situá-lo no processo não apenas como um sujeito que parte em busca do desconhe- cido, mas, na coletividade, como o viajante em busca do outro.

$\mathrm{Na}$ travessia, sejam nas motivações, descobertas e/ou (des)encontros, busco perceber, como alerta lanni (2000, p. 28), que os caminhos do mundo não estão traçados: "Ainda que haja muitos desenhados nas cartografias, emaranhados nos atlas, todo viajante busca abrir caminho novo, desvendar o desconhecido, alcançar a surpresa ou o deslumbramento. A rigor, cada viajante abre seu caminho, não só quando desbrava o desconhecido, mas inclusive quando redesenha o conhecido". O poeta Antonio Machado (2003, p. 17) assegura: “Caminante, no hay camino, se hace camino al andar, al andar se hace el caminho, y al volver la vista atrás se ve la senda que nunca se ha de volver a pisar"2. Assim, convida-nos a pensar que o caminho não se faz sozinho. Os interesses em comum reuniram, durante séculos, sujeitos em busca de novos destinos, que, nas travessias, traçaram seus próprios caminhos.

As relações dão-se entre as diferentes nacionalidades, temporalidades e destinos. 0 estudo da história, de acordo com Lopes e Galvão (2005), nos oferece a oportunidade de uma ampliação semelhante àquela obtida nas viagens. Seja no próprio deslocamento ou na viagem que ora fazemos através dos registros, findamos por nos deparar com o outro, no tempo e no espaço. Apesar desse encontro não resultar diretamente em uma mudança no olhar do pesquisador ou do viajante, é certo que o encontro com o diferente pode possibilitar, por aproximação e estranhamento, a distinta compreensão de si e da sua própria cultura. A relação, direta ou indireta com o outro, nos aponta o quanto somos universais e, ao mesmo tempo, particulares.

Nestor Lima representa a história que se constrói no itinerário. Essa construção se dá

2 "Caminhante, não há caminho, se faz caminho ao andar, ao andar se faz o caminho e ao voltar a vista atrás se vê a senda que nunca se há de voltar a pisar". 
a partir do caminho percorrido, mencionando pessoa a pessoa que encontrou, detalhes dos comportamentos em relação à receptividade em determinadas instituições e como cada sujeito é ponte para novo contato:

Encontrei por parte das autoridades e dos profissionais do ensino na Argentina, no Uruguai, em São Paulo, em Belo Horizonte e no Rio, um intenso desejo de permutação de esforços, no sentido de conhecermo-nos reciprocamente acompanharmos com o interesse devido todas as realizações atinentes ao problema educativo e avaliarmos os resultados obtidos com as modificações do aparelho e da técnica pedagógica. (LIMA, 1923, p. 5)

Os contatos sociais e as viagens possuem um movimento intrínseco, que o torna capaz de ampliar seu conhecimento, aprimorar saberes e revelar novos referenciais. A viagem, por meio dos olhos e da escrita do viajante, o coloca em contato com dois mundos. Tendo visto a constituição das redes, busco ver também sua ampliação a partir da visitação de novos espaços. No tópico do relatório intitulado "Outras impressões", revelam-se importantes elementos culturais da viagem. É nesta etapa que o viajante abre um espaço para dizer que, além das visitas escolares, fez outras três que, para ele, eram importantes:

O Jardim Zoológico, em Palermo, é uma curiosidade legítima em Buenos Aires; frequentado por uma multidão, aos domingos, o jardim é provido de várias espécies de animais, de quase todos os climas e habitats do mundo, especialmente da fauna sul-americana. Ali vi várias espécies de animais brasileiros. Notei que as placas lembravam aos visitantes: "cuidado com os ladrões, os contos de tio, as mães enfermas e os filhos falecidos por enterrar", sortes de alegações e lamurias que os desocupados iludem e vitimam os incautos, que por ali passam desocupadamente [...] Palermo é um bairro urbano, só de jardins e logradouros: para ali aflui o povo, as crianças, os turistas, mesclando nas toiletes, nas línguas, nos esportes, toda uma população cosmopolita, como é a de Buenos Aires. (LIMA, 1923, p. 50)

Visitou também o Museu Histórico argentino, onde viu diferentes fases da história da Argentina, através dos seus tipos, modas, costumes, vestimentas, armas, documentos e feitos, perfeitamente arquivados e expostos à visão curiosa dos estrangeiros. “O grande número de telas, croquis, retratos, panoramas, aumenta o interesse dessa visita" (LIMA, 1923, p. 50). No teatro, à época considerado o mais amplo da América do Sul, esteve Nestor Lima, na tarde de 16 de maio, para assistir, com os inspetores Alonso e Picarel, uma homenagem das sociedades teatrais portenhas a Camilla Quiroga:

Por uma diferença especial da Administração do Teatro, foi nos cedida uma tribuna presidencial, para o que foi bastante que se lembrasse a minha condição de brasileiro em missão oficial ali. [...] A homenagem foi grandiosa, os oradores exaltaram a arte argentina e a sua representante com a mesma exageração que nós brasileiros usamos as nas nossas apologias e panegíricos.... São os excessos do meridional. Uma orquestra com mais de cem figuras, sob a batuta do maestro italiano Malvagni, encheu a solenidade, que o pianista russo ilustrou Zadora ilustrou, com o fulgor do seu talento magistral. (LIMA, 1923, p. 51)

O enfoque no prestígio do funcionário em comissão ressoa nas palavras de Nestor Lima, ao contar o fato acontecido. Transitar por outros países, estudar e conhecer a cultura do estrangeiro era uma realidade de vida dos jovens aristocratas; os mesmos que frequentavam as primeiras Faculdades de Direito, Medicina e Engenharia, e eram subsidiados com auxílios, motivados a viajar para expandir seus conhecimentos nas diversas áreas: literatura, artes, história antiga e moderna, comércio e diplomacia. Por algum destes motivos, ocupavam cargos públicos, estavam à frente das discussões e rumos da educação nacional. Os intelectuais reformadores, com o objetivo de 
fazer valer seus "projetos de ensino e visões sobre educação", usaram a palavra, seus conhecimentos e capitais acumulados (CARDOSO; MORAES, 2014, p. 24).

Conhecer, ainda, os costumes locais dos lugares visitados, através da música e do teatro, tornando-se assim familiarizados com cidades e países das mais diversas culturas e práticas. Desse modo, inspetores de ensino, diretores e professores e até engenheiros, médicos e políticos, envolvidos com projetos educacionais, foram em busca dos códigos de civilização. Moda, língua, religião, modelos econômicos e educacionais; os países considerados mais avançados ou com maior produção cultural legitimada servem como unidades de referência, que podem ser trazidas à luz para vários argumentos políticos.

No Brasil, Nestor Lima também realizou visitas para além dos espaços educacionais. Em São Paulo, faz visitas às companhias editoriais, a exemplo da Companhia Melhoramentos, que, em 1922, publicou 344.000 volumes e a Monteiro Lobato e Companhia, consagrada à publicação de obras literárias. Tece comentários acerca do Museu Pedagógico de São Paulo, considerando-o como: "[...] ligeiro ensaio de colecionamento dos trabalhos infantis, quer de lições, quer de simples lazer dos alunos. Reúnem-se espécies de escolas da capital e do interior" (LIMA, 1923, p. 58). Esteve ainda em outras instituições paulistas como o Museu do Ipiranga, onde menciona ter recebido do diretor do Museu uma coleção completa das suas publicações, para o Instituto Histórico e Geográfico do Rio Grande do Norte/IHGRN. Apresenta com detalhes as obras do Monumento do Centenário, onde, segundo ele, são proclamadas as grandezas da Pátria:

Lá estava o retrato histórico do Ypiranga, o plano gigantesco de Ettore Ximenes, onde se vê, sob um colossal bloco facetado, um carro de vitória, onde se proclamam na tuba da fama as grandezas da Pátria. Nas faces do bloco, pela frente, um grupo enorme de momento histórico do grito libertário, de acordo com a visão de Pedro Américo, tudo em Bronze e em tamanho natural; à direita, o martírio de Tiradentes; à esquerda, um motivo sobre a revolução de 1817, tendo em vários grupos alegóricos e votivos do nosso passado heroico. Cerca-o imenso jardim, que se vai ligar à majestosa avenida, porque também se liga à cidade do Braz na direção de Santos. Não é possível, mesmo nos adjetivos empregados acima, toda a emoção daquela visita. Tenho a impressão de que cada brasileiro deveria ir até ali, admirar naquele esforço de arte e decoração, o nosso passado histórico e reverenciar, como numa catedral da Pátria, os grandes heróis da nossa libertação. Deveria ser ali o lugar sagrado das nossas romarias cívicas: o altar da Pátria brasileira. (LIMA, 1923, p. 72)

Nestor Lima revela-se, na narrativa, por entre os espaços visitados e as redes estabelecidas. Seus interesses, a forma como rememora características das pessoas que conheceu ou reencontrou, bem como das instituições, suas práticas e organizações, falam muito mais do olhar deste sujeito do que no primeiro momento se pode perceber. Viñao Frago (2000, p. 2) afirma que: "la memoria no es un espejo, sino un filtro, y lo que sale, a través del filtro, no es nunca la realidad misma, sino una realidad siempre recreada, reinterpretada y a veces, incluso, consciente o inconscientemente imaginada hasta tal punto que puede llegar, en la mente del que recuerda, a sustituir, con ventaja, a lo realmente acaecido". ${ }^{3}$

\section{Palavras de Despedida}

$\mathrm{Na}$ realidade ou metaforicamente todos realizamos viagens. Ao ler o relatório de Nestor dos Santos Lima senti-me como quem o acom-

\footnotetext{
3 "A memória não é um espelho, mas um filtro, e o que sai, através do filtro, não é nunca a mesma realidade, mas uma realidade sempre recriada, reinterpretada e às vezes, mesmo, consciente ou inconscientemente imaginada até tal ponto que se pode chegar, na mente do que se lembra, a substituir, com vantagem, o que realmente aconteceu."
} 
panhasse, fizesse parte dos momentos descritos. Imaginei os caminhos trilhados por Nestor Lima, não só nas viagens comissionadas, mas os caminhos de vida, de construção. No curso da travessia, por vezes revela-se a identidade, que é recriada no encontro com a diversidade e, para percebê-la, inúmeros distanciamentos foram realizados. Desejei que a vida viesse à tona, revelasse o educador para além do que o impresso pode comportar.

A viagem é aqui entendida como aquisição de experiência e autoconstrução, que se revela como aventura intelectual, num movimento destinado sempre à ultrapassagem de fronteiras estabelecidas, como afirma Ianni (2000), a viagem descortina pluralidades. A escrita de si presente no documento oficial revela o diálogo entre a identidade pessoal e profissional de um indivíduo e, de acordo com Mignot (2002, p. 62), elas "se constroem, há uma interação, uma porosidade entre elas. Sua complexidade é acessivel na medida em que se pode identificar processos parciais de formação, em permanente diálogo".

As observações e representações construídas pelo autor, ao longo do trajeto, permitem também a criação de representações sobre si. Reflito que não só a memória, mas a posição social ocupada por ele e o endereço final de entrega do relatório de viagem já representavam alguns dos filtros que podem ter retido informações, apreciações, elucidando desse modo as escolhas de Nestor Lima. Talvez muitos de seus pensamentos sequer tenham chegado ao papel e quantas outras opiniões podem ter sido rasuradas em um rascunho, dando espaço para as que naquele momento mereciam destaque? Explorar os sentidos da escrita de si, nas narrativas de um educador viajante, é se lançar em busca do que não se entrega de graça, é realizar uma nova viagem, agora de outra forma, transitando por entre o que ele escreveu e a leitura que eu realizo.
Educação e educador possuem espaços bem delineados e o relatório de viagem suporta muito mais vida e movimento do que se pode esperar, em se tratando de um escrito produzido a partir de uma missão profissional. Em meio aos pré-requisitos que compõem a escrita de um documento oficial, há as emoções do sujeito traduzidas nos contatos estabelecidos, no visto e no vivido. Seus anseios, impressões e julgamentos são apresentados com clareza. Assim como o carinho, respeito e divergência de ideias saltam as páginas, anunciando seus posicionamentos frente às situações e pessoas encontradas pelo caminho.

Dentre as tantas estratégias de legitimação que sutilmente são percebidas no relatório de viagem, demonstrando a rede de conhecimento teórico e pessoal, o domínio de um idioma e a postura de traduzir o conhecimento para o povo de seu Estado de origem, fazem com que não só a viagem seja propagada, mas também o sujeito que a realizou. De acordo com Mignot (2007, p. 252), "O contato com o que se passava em outros países, com outros povos, conferia credibilidade às opiniões emitidas e visibilidade às causas pelas quais a viajante se empenhava". O caráter testemunhal é um ponto de relevância, quando se trata de relatos de viagem, visto que versa com mais objetividade sobre o visto e o vivido, bem como sobre a proximidade e o compromisso com o que se narra. Os relatos de viagem se nutrem da experiência do viajante.

São muitas facetas de um só viajante. Ora o enxergo como o viajante sedento pelas experiências culturais, visitas à museus, exposições, teatros e até zoológicos. Em outros momentos, é o advogado que, atento às questões da lei, busca inteirar-se dos melhoramentos no funcionamento do sistema penitenciário paulista, e por razões outras, o cidadão curioso acerca dos avanços da medicina. Entendo que todas estas áreas sociais dialogam com os aspectos que considerava relevante para a formação do 
cidadão e, de modo direto ou indireto, os interesses que o encaminham para os lugares que merecem espaço em sua narrativa.

A escrita que Nestor dos Santos Lima desenvolve no relatório oficial é constituída pelo constante movimento de olhares de familiaridade e estranhamento que denotam a inspiração para a execução de novas práticas, a recusa de alguns modelos vistos em desenvolvimento e a possivel legitimação das mudanças as quais julgou carecer a realidade educacional norte-rio-grandense. Por entre as linhas do seu relatório de viagem, configuram-se suas redes e os espaços de sociabilidade.

\section{Referências}

ALBUQUERQUE-GARCÍA, Luís. El 'Relato de viajes': hitos y formas em la enolución del género. Revista de Literatura, Madrid, Instituto de Lengua, Literatura y Antropología, vol. LXXIII, n. 145, p. 15-34. jan./ jun. 2011.

AMORIM, Sara Raphaela Machado de. Viagem como missão: intercâmbio pedagógico do educador Nestor dos Santos Lima (1913-1923). 2017. 198f. Tese (Doutorado em Educação) - Programa de Pós-Graduação em Educação/ProPEd, Universidade do Estado do Rio de Janeiro, Rio de Janeiro, 2017.

CARDOSO, Silmara de Fátima; MORAES, Dislane Zerbinatti. Viajar é inventar o futuro: narrativas de formação e o ideário educacional brasileiro nos diários e relatório de Anísio Teixeira em viagem à Europa e aos Estados Unidos (1925-1927). Jundiaí: Paco Editorial, 2014.

CASTILlO GÓMEZ, Antonio. La Corte de Cadmo: apuntes para una historia social de la cultura escrita. Revista de Historiografia, Madrid, n. 1, p. 89-98, 2004.

CHAMON, Carla Simone; FARIA FILHO, Luciano Mendes de. A educação como problema, a América como destino: a experiência de Maria Guilhermina.
Castillo Gómez (2004, p. 94) afirma que “la escritura puede ser todo aquello que nosotros seamos capaces de leer en ella" ${ }^{\prime 4}$. Com o intuito de explorar os sentidos autobiográficos nas narrativas de Nestor dos Santos Lima, persegui os múltiplos significados que sua escrita revela, investigando desde os fatores que o inseriram na condição de representante do Estado, como também os caminhos e relações do educador viajante que deixou rastros de si no que se propôs a produzir. As considerações que neste momento pressupõem uma despedida são, na verdade, o passaporte para o próximo destino.

4 "A escrita pode ser tudo aquilo que nós sejamos capazes de ler nela".

In: MIGNOT, Ana Chrystina Venancio; GONDRA, José Gonçalves. (Orgs.). Viagens pedagógicas. São Paulo: Cortez, 2007. p. 39-64.

O olhar comparativo: Estevão de Oliveira e os grupos escolares em Minas, no Rio e em São Paulo. Revista Brasileira de História da Educação, n. 22, p. 17-41, jan./abr. 2010.

CHARTIER, Roger. A história cultural: entre práticas e representações. Tradução de Maria Manuela GaIhardo. Rio de Janeiro; Lisboa: Difel, 1990.

IANNI, Octávio. A metáfora da viagem. In: Enigmas da modernidade-mundo. Rio de Janeiro: Civilização Brasileira, 2000, p. 11-31.

LIMA, Nestor dos Santos. Da organização do ensino normal, profissional e primário no sul do Brasil e no Rio da Prata. Natal: Typ. d'A República, 1923.

Melhoramentos técnicos do ensino primário e normal. Natal: Typ. Do Instituto, 1913.

LOPES, Eliana Marta Teixeira; GALVÃO, Ana Maria de Oliveira. História da Educação. Rio de Janeiro: DP\&A, 2005.

MACHADO, Antonio. Provérbios y cantares. Madri: El País, clasicos del siglo XX, 2003. 
MIGNOT, Ana Chrystina Venacio. Entre cartas e cartões postais: uma inspiradora travessia. In: MIGNOT, Ana Chrystina Venâncio; GONDRA, José Gonçalves. Viagens Pedagógicas. (Orgs). São Paulo: Cortez, 2007. p. 246-276.

Baú de memórias. Bastidores de histórias: o legado pioneiro de Armanda Álvaro Alberto. Bragança Paulista: EDUSF, 2002.

MIGNOT, Ana Chrystina Venacio; SILVA, Alexandra Lima da. Tão longe, tão perto: escrita de si em relatórios de viagens. Educação em Revista, Belo Horizonte, v. 27, n. 1, p. 435-458, abr. 2011.

MIGNOT, Ana Chrystina Venacio; GONDRA, José Gonçalves. (Orgs). Viagens pedagógicas. São Paulo: Cortez, 2007.

MOITA, Maria da Conceição. Percursos de formação e de trans-formação. In: NÓVOA, António. (Org.). Vidas de professores. Portugal: Porto, 1992. p. 111-139. MORAIS, Maria Arisnete Câmara de. História dos impressos e a formação da leitora no século XIX. In: CURY, Cláudia Engler; MARIANO, Serioja. (Orgs.). Múltiplas visões: cultura histórica no oitocentos. João Pessoa: Editora Universitária da UFPB, 2009. p. 75-98.

SCHUELER, Alessandra. A longa peregrinação de um professor da roça na Europa. In: MIGNOT, Ana Chrystina Venancio.; GONDRA, José Gonçalves. (Orgs.). Viagens pedagógicas. São Paulo: 2007. p. 90-113.
SILVA, Alexandra Lima da. Escritas de viagem, escritas da história: estratégias de legitimação de Rocha Pombo no campo intelectual. 2012. 266 f. Tese (Doutorado em Educação) - Programa de Pós-Graduação em de Educação/ProPEd, Universidade do Estado do Rio de Janeiro, Rio de Janeiro, 2012.

SIMMEL, Georg. Sociabilidade: um exemplo de sociologia pura ou formal. In: MORAES FILHO, Evaristo. (Org.). SIMMEL, Georg. Sociologia. São Paulo: Ática, 1997. p. 165-181.

SIRINELLI, Jean-François. Os intelectuais. In: REMOND, R. (Org.). Por uma história política. Rio de Janeiro: Fundação Getúlio Vargas, 2003. p. 231-269.

VENANCIO, Gisele Martins. Presentes de papel: cultura escrita e sociabilidade na correspondência de Oliveira Vianna. Estudos Históricos, Rio de Janeiro, n. 28, p. 23-47, 2001.

VINÃO FRAGO, Antonio. 2000. Las autobiografias, memórias y diários como fuentes histórico-educativas: tipologia e usos. Teias: Revista da Faculdade de Educação da UERJ, Rio de Janeiro, n. 1, p. 1-26 , jun. 2000. Disponivel em: http://www.e-publicacoes. uerj.br/index.php/revistateias/article/view/23827. Acessado em: 20/03/2017.

Recebido em: 20.03.2017

Aprovado em: 01.08.2017

Sara Raphaela Machado de Amorim é Doutora em Educação pelo ProdPed/UERJ. Professora da Universidade do Estado do Rio Grande do Norte. Líder do Núcleo de Pesquisa em Educação/NUPED-UERN. e-mail: raphaela.amorim@hotmail.com

Avenida Ceará, no 73, Cidade da Esperança. CEP: 59071-110 - Natal/RN.

Telefone: (84) 99878-7273 